\title{
Sertraline increased the response rate and improved symptoms in post-traumatic stress disorder
}

Brady K, Pearlstein T, Asnis GM, et al. Efficacy and safety of sertraline treatment of posttraumatic stress disorder: a randomized controlled trial.JAMA 2000 Apr 12;283:1837-44.

QUESTION: In patients with post-traumatic stress disorder (PTSD), is sertraline effective for improving symptomatic outcomes?

Source of funding:

Pfizer Inc.

For correspondence: Dr K Brady,

Department of

Psychiatry, Medical

University of South

Carolina, 67 President

Street, $P O B$ Box

250861, Charleston

SC 29425, USA. Fax

+18437927353 . (unclear)*, placebo controlled trial with 12 weeks of follow up.

\section{Setting}

Outpatient clinics in 8 academic medical centres and 6 clinical research centres in the US.

\section{Patients}

187 patients who were $\geq 18$ years of age (mean age 40 y, 73\% women); had PTSD according to DSM-III-R criteria for at least 6 months with a severity score $\geq 50$ on the Clinician Administered PTSD Scale, Part 2 (CAPS2); and had not taken psychotropic medication in the previous 2 weeks. Exclusion criteria included history of bipolar, schizophrenic, or other psychotic disorder; organic mental disorder; factitious disorder or malingering; primary diagnosis of major depression, obsessive compulsive disorder, or other anxiety disorders; acute or unstable medical conditions; contraindication to sertraline; pregnancy; cognitive behavioural therapy (CBT) during the trial; and psychotherapy that began or ended during the trial. $71 \%$ of patients completed the study, and 98\% had $\geq 1$ assessment after randomisation.

\section{Intervention}

Patients were allocated to sertraline $(n=94)$ or placebo $(\mathrm{n}=93)$ for 12 weeks. Sertraline was given at an initial dose of $25 \mathrm{mg}$ /day for 1 week with flexible daily dosing and 50-200 mg/day thereafter (mean dose 133.3 $\mathrm{mg}$ /day).

\section{Main outcome measures}

Response ( $\geq 30 \%$ reduction from baseline in CAPS-2 total severity score and Clinical Global ImprovementImprovement [CGI-I] score of 1 or 2), total severity score on the CAPS-2, the Impact of Event Scale (IES), and the investigator rated CGI-Severity and CGI-I scales.

\section{Main results}

Analysis was done using last observation carried forward. More patients in the sertraline group than in the placebo group responded to treatment $(p=0.008)$ (table). Sertraline led to greater improvement from baseline on the CAPS-2 ( $\mathrm{p}=0.02)$ (table) and the CGI-S total scores (mean change from baseline scores $-1.2 v$ $-0.8, \mathrm{p}=0.01$ ) than did placebo. At 12 weeks, scores on the CGI-I were better for sertraline than for placebo (mean scores $2.5 v 3.0, \mathrm{p}=0.02$ ). A trend existed towards greater improvement on the IES $(p=0.07)$ (table).
In patients with post-traumatic stress disorder, sertraline increased the response rate and improved symptoms.

*See glossary.

Sertraline v placebo for post-traumatic stress disordert

\begin{tabular}{|c|c|c|c|c|}
\hline Outcomes at 12 weeks & Sertraline & Placebo & $\mathrm{RBI}(95 \% \mathrm{Cl})$ & NNT (Cl) \\
\hline \multirow[t]{3}{*}{ Response rate } & $53 \%$ & $32 \%$ & $64 \%(16$ to 135$)$ & 5 (3 to 17$)$ \\
\hline & \multicolumn{2}{|c|}{$\begin{array}{l}\text { Mean change from } \\
\text { baseline }\end{array}$} & \multirow{2}{*}{\multicolumn{2}{|c|}{$\begin{array}{l}\text { Difference in mean change from } \\
\text { baseline }(\mathrm{Cl})\end{array}$}} \\
\hline & Sertraline & Placebo & & \\
\hline CAPS-2 total score & -33.0 & -23.2 & \multicolumn{2}{|l|}{9.8 (1.8 to 17.8$)$} \\
\hline IES total score & -16.2 & -12.1 & \multicolumn{2}{|l|}{$4.1(-0.4$ to 8.6$) \ddagger$} \\
\hline
\end{tabular}

†CAPS-2=Clinician Administered PTSD Scale, Part 2; IES=Impact of Event Scale. Other abbreviations defined in glossary; RBI, NNT, $\mathrm{Cl}$, and mean differences calculated from data in article. $\ddagger$ Not significant.

\section{COMMENTARY}

This study by Brady et al is the largest published randomised controlled trial (RCT) of any treatment modality for PTSD and strengthens the existing evidence about the effectiveness of antidepressants in PTSD. ${ }^{1}$

The participants had developed PTSD secondary to various different traumatic events and were recruited from both academic and non-academic centres in the US. The results are therefore potentially more generalisable than those of other studies with smaller samples from a single trauma such as war or sexual assault. The mean duration of illness of 12 years would probably have made treatment less likely to be beneficial than if the duration of illness had been shorter. Another important aspect is that the mean sertraline dose was $133.3 \mathrm{mg} /$ day ( $151.3 \mathrm{mg} / \mathrm{d}$ for study completers), which is relatively high compared with the $50-100 \mathrm{mg} /$ day dose usually prescribed in clinical practice.

The increased effectiveness of sertraline over placebo is convincing but the magnitude of the effect is not great. The mean difference in reductions on the CAPS-2 and IES (2 widely used and well validated measures of PTSD) are modest and would not represent major differences clinically. This should not prevent clinicians prescribing sertraline or other antidepressants to people with PTSD, but it would be wrong to think of antidepressant medication as a cure. Overall, the effect sizes in psychological treatment studies have been greater but the methodology poorer. ${ }^{2}$ Indeed, many psychological treatment trials have used waiting list controls or unconvincing "placebo" controls, making direct comparison of effect sizes with this trial virtually impossible.

This study adds to the evidence that enables clinicians to offer people with PTSD a choice of evidence-based treatments (subject to availability). Psychological treatments including CBT and eye movement desensitisation and reprocessing have been supported in RCTs, ${ }^{2}$ as have antidepressants, including amitriptyline, phenelzine, fluoxetine, and now sertraline. ${ }^{1}$

$$
\begin{array}{r}
\text { Jonathan I Bisson, DM, MRCPsych } \\
\text { Gabalfa Clinic } \\
\text { Cardiff, UK }
\end{array}
$$

1 Penava SJ, Otto MW, Pollack MH, et al. Current status of pharmacotherapy for PTSD: an effect size analysis of controlled studies. Depress Anxiety 1996-97:4:240-2.

2 Sherman JJ. Effects of psychotherapeutic treatments for PTSD: a meta-analysis of controlled clinical trials. J Trauma Stress 1998;11:413-35. 